\title{
Desain dan Implementasi Virtual Laboratory Materi Osilator Analog berbasis IC OP-AMP
}

\begin{abstract}
SYIFAUL FUADA, AJI WIDHI WIBOWO
Sekolah Pascasarjana Sekolah Teknik Elektro dan Informatika (STEI) Jurusan Teknik Elektro Microelectronic Engineering Institut Teknologi Bandung Email: syifaulfuada@students.itb.ac.id

ABSTRAK

Laboratorium virtual merupakan salah satu platform laboratorium modern yang dapat mendukung kegiatan praktikum yang berjalan secara tradisional (Hand-on Laboratory). Penelitian ini bertujuan untuk mendesain dan mengimplementasikan Virtual Laboratory pada materi pembangkit sinyal dengan subtopik: Wien Bridge sebagai osilator RC, Hartley dan Colpitts sebagai osilator LC dan Astable Multivibrator sebagai osilator relaksasi, yang dibangun berbasis IC Operational Amplifier (OP-AMP). Jenis penelitian ini merupakan $R \& D$ yang terdiri dari enam tahapan, yaitu: konsep, desain, pengumpulan bahan, pembuatan, pengujian dan pendistribusian. Aplikasi perangkat lunak berbasis dekstop ini telah diuji secara fungsional dengan 6 (enam) aspek parameter yakni: uji polaritas kapastor; uji wiring; uji mode frekuensi dan mode perioda pada alat ukur frequency generator; uji specific decission pada trainer kit osilator hartley dan colpitts; uji kesesuaian antara frekuensi ouput dari masing-masing osilator dengan perhitungan teorema dan hasil percobaan sesungguhnya; dan uji kualitas media. Hasil secara keseluruhan telah sesuai dengan ekspektasi didalam story board.
\end{abstract}

Kata kunci: IC OP-AMP, Osilator analog, Laboratorium virtual

\begin{abstract}
The Virtual Laboratory is as one of modern laboratory platform which able to support the hand-on worklab. The goal of this research are for designing and implementing a Virtual Laboratory of signal generator material with subtopics i.e. the Wien Bridge as an RC oscillator, the Hartley and Colpitts as LC oscillator and the astable multivibrator as relaxation oscillator which assembled based on Operational Amplifier Integrated Circuit (OP-AMP). This research is $R \& D$ type which consists of six stages, i.e. concept, design, materials collection, assembling, testing and distribution. This desktop-based software application has been functionally tested with six aspect of parameters such as: capacitor polarity testing; wiring testing; testing of frequency mode and period mode in frequency counter instrument; Specific decission test of the hartley and colpitts oscillator; fit-test for comparasion results between output frequency from each of oscillators with theorem calculations and actual experimental results; and quality test of media. The overall results was in line in expectations based on the story board.
\end{abstract}

Keywords: Analog oscillator, IC OP-AMP, Virtual Laboratory 


\section{PENDAHULUAN}

Osilator merupakan salah satu bagian dari sistem elektronika yang berfungsi untuk membangkitkan frekuensi dalam bentuk sinusoida, square, sawtooth atau segitiga (Manchini, 2001). Materi osilator disajikan dalam mata kuliah hampir di berbagai perguruan tinggi di Indonesia yang mempunyai jurusan ilmu rumpun elektro baik eksak maupun kependidikan. Laboratorium merupakan salah satu prasarana pendidikan yang harus dimiliki oleh suatu institusi pendidikan yang memiliki jurusan dibidang ilmu sains dan teknologi. Berfungsi sebagai wadah proses pembelajaran berbasis praktik atau eksperimental yang didalamnya memuat berbagai macam alat praktikum, alat ukur, komponen atau bahan lainnya untuk mendukung keberhasilan tujuan belajar.

Salah satu tantangan yang dihadapi oleh laboratorium elektronika di berbagai institutsi pendidikan di Indonesia adalah keterbatasan alat ukur karena umumnya pengadaan barang secara ekspor dari luar negeri sehingga harga cenderung mahal. Terdapat dua solusi yang ditawarkan untuk mengatasi permasalahan tersebut yakni dengan membuat perangkat praktikum sendiri seperti yang dilakukan oleh (Darlis, 2013) dengan judul penelitian "Perancangan dan Realisasi Sistem Pentransmisian Short Message dan Sinyal Digital pada Modem BPSK berbasis MATLAB' yakni membuat instrument pengganti audio generator, dimana sistem ini dapat diaplikasikan untuk praktikum telekomunikasi dengan kelebihan mempunyai fitur lebih lengkap dan ekonomis dibandingkan alat yang sudah ada saat ini. Penelitian lain dilakukan oleh (Kharisma, 2013) dan (Supriandani, 2015) dengan membuat piranti alat ukur oscilloscope berbasis PC, terobosan yang ditempuh ini dapat membantu laboratorium elektronika dalam pengadaan alat instrumentasi yang lebih ekonomis. Solusi yang kedua adalah dengan membuat sebuah terobosan pengembangan media sebagai suplemen bahan ajar pembelajaran praktikum yang sejauh ini dapat dilakukan dengan dua model pendekatan, yakni Augmented Reality atau ARLAB dan Virtual Laboratory atau biasa disebut dengan istilah $V L A B$.

Tentu asing-masing terdapat kelebihan dan kekurangannya. Apabila membuat perangkat praktikum sendiri maka produk haruslah sesuai dengan standar ISO atau standar rujukan lainnya serta memiliki kualitas yang setara dengan alat instrumentasi yang sesungguhnya. Oleh karena itu produk harus dibangun dengan komponen-komponen elektronika khusus atau spesifik dan melalui metodologi tertentu agar memiliki tingkat akurasi ketelitian dan kepresisian yang tinggi sehingga memadai untuk dipakai.

Begitu pula dengan pembuatan media pembelajaran bahwa media harus sesuai standar pendidikan dan dapat mewakili praktikum yang sebenarnya (Potkonjak, 2016) sehingga dapat dipergunakan oleh peserta didik yang memiliki keterbatasan akses akan alat-alat laboratorium. Karena pada dasarnya media pembelajaran merupakan salah satu model pendekatan untuk membantu mengetahui, memahami dan menganalisis fenomenafenomena tertentu yang terdapat dalam suatu bidang ilmu. Disamping itu salah satu prinsip media pembelajaran adalah tidak terbatas dipakai pada saat kapanpun dan dimanapun oleh siapapun yang ingin mengoperasikan.

Dalam kaitan antara laboratorium tradisional (hand-on lab.) dengan laboratorium modern, laboratorium tradisional membutuhkan perangkat yang riil/sebenarnya. Seperti pada kasus praktikum osilator, yakni: kabel probe dan osiloskop, project board, komponen OP-AMP, transistor, resistor, kapasitor, induktor, dan frequency counter. Karena perangkat yang khusus inilah terkadang memiliki keterbatasan waktu dalam melakukan eksperimen, karena:

1. Alokasi waktu antara kelas satu dengan kelas lainnya untuk memakai laboratorium terbatas; 
2. Alat ukur seperti osiloskop tidak diijinkan dibawa pulang karena harga yang relatif mahal;

3. Kemampuan, kecakapan dan kecekatan antar peserta didik dalam satu kelas tidaklah sama, distribusi yang umumnya tidak merata ini menjadikan beberapa kelompok praktikum ada yang tertinggal, hal ini menjadikan tujuan belajar tidak tercapai.

Laboratorium virtual merupakan salah satu bentuk laboratorium modern yang cukup membantu institusi, pendidik ataupun peserta didik dalam penyelenggaraan pembelajaran berbasis praktikum. Peserta didik yang memiliki akses terbatas ke perangkat yang hanya terdapat di laboratorium tersebut tetap dapat melakukan di luar jam pembelajaran, yakni melalui pemanfaatan perangkat umum yang sudah mereka miliki. Misalnya dengan menggunakan PC atau gadget lainnya. Banyak manfaat yang ditawarkan melalui laboratorium virtual, yakni:

1. Peserta didik dapat memanfaatkannya jika tidak ada cukup waktu untuk menyelesaikan praktikum di laboratorium, sehingga diharapkan dapat mempercepat pencapaian suatu kompetensi tertentu;

2. Pemanfaatan teknologi ini sangat tepat diterapkan dalam mengganti praktikum yang menggunakan alat peraga berharga sangat mahal serta hanya satu-satunya di laboratorium tersebut;

3. Tepat diterapkan untuk menggantikan alat praktikum yang dinilai mengandung resiko kecelakaan kerja, misalnya rawan sengatan listrik tinggi (Budhu, 2011) dan

4. Dapat meningkatkan kompetensi peserta didik terutama siswa SMK dari segi kognitif dan psikomotorik sekaligus memfasilitasi pendidikan karakter peserta didik yang bersangkutan (Jaya, 2012). Pengembangan perangkat lunak Virtual Laboratory ini memiliki potensial untuk memberikan peningkatan secara signifikan dan pengalaman belajar yang lebih efektif.

Peneltian ini berfokus pada pendekatan yang kedua, yakni pengembangan media. Oleh karena itu tujuan dari penelitian ini adalah mendesain dan mengimplementasikan virtual laboratory pada materi osilator/pembangkit sinyal dengan sub topik: Wien Bridge oscillator, Hartley oscillator, Colpitts oscillator dan Astable Multivibrator berbasis IC Operational Amplifier (OP-AMP). Perangkat lunak ini dibangun menggunakan aplikasi adobe flash, karena memiliki beberapa keunggulan, yakni:

1. Memiliki interaktivitas dan motion animation yang baik;

2. Bahasa pemrogaman berbasis actionscript yang sangat simple namun powerful;

3. Dapat merepresentasikan objek dengan tingkat tampilan yang baik (Reimers, 2007).

Pengembangan Virtual Laboratory dengan topik osilator ini merupakan kelanjutan yang berkesinambungan dari penelitian-penelitian yang dilakukan oleh penulis sebelumnya yakni:

1. Analisis Oscillator Astable Multivibrator IC 741UA Menggunakan Pendekatan Matlab dan Software Elektronik (Fuada, 2013);

2. Pengujian Trainer Osilator Wien Bridge (Jembatan Wien) dengan Menggunakan Osciloskop dan Frekuensi Counter (Fuada, 2014);

3. Design and Fabrication of LC-Oscillator Tool Kits Based Op-Amp for Engineering Education Purpose (Fuada, 2016).

Penulis terus mengembangkan perangkat ajar yang berhubungan dengan harapan agar dapat dipergunakan oleh peserta didik untuk lebih memahami osilator dan aplikasinya pada devais elektronika tertentu. Platform pada Virtual Laboratory ini mengacu pada peneltiian skripsi (Fuada, 2014). 


\section{METODOLOGI PENELITIAN}

\subsection{Model Pengembangan}

Peneliti menggunakan model (Hadi, S., A., 2003) sebagai metode untuk menghasilkan produk Virtual Laboratory. Penelitian terdiri dari 6 (enam) tahapan, yaitu concept, design, material collecting, assembly, testing dan distribution.

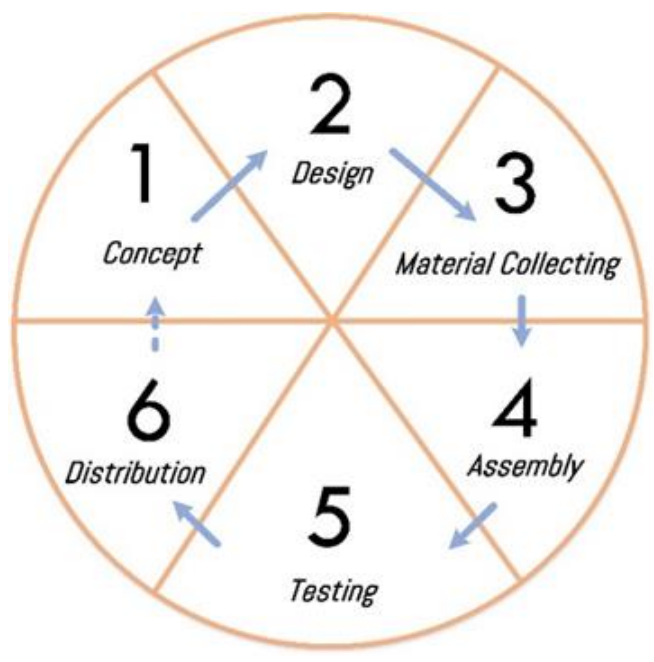

Gambar 1. Tahapan dalam pengembangan Multimedia (Hadi, 2003)

\subsection{Prosedur Penelitian}

\section{Concept}

Aplikasi yang diusulkan merupakan aplikasi perangkat lunak tentang Virtual Laboratory dengan materi osilator analog berbasis OP-AMP. Antarmuka disajikan secara 2 dimensi yang ditampilkan pada layar dekstop PC. Perangkat lunak yang dibuat hanya untuk melakukan aktivitas praktikum, yakni praktikum (1) Osilator Wien Bridge. (2) Osilator Hartley; (3) Osilator Colpitts dan (5) Astable Multivibrator. Pada window praktikum, semua perangkat pendukung eksperimen telah tersedia, pengoperasian perangkat lunak ini adalah dengan melakukan aktivitas plug and play dari ke virtual trainer kit ke modul Resistor/ Kapasitor/ Induktor. Praktikan melihat besaran frekuensi yang dihasilkan melalui alat ukur yang telah disediakan, dalam hal ini adalah frequency counter.

\section{Design}

Pada tahap desain, terdapat beberapa aktivitas yakni penentuan perangkat lunak seperti yang ditunjukkan pada Tabel 1 , selanjutnya adalah penentuan spesifikasi perangkat keras untuk membangun Virtual Laboratory yang digunakan selama penelitian (ditunjukkan pada Tabel 2), properties yang harus dibuat sebagai komponen penyusun Virtual Laboratory (ditunjukkan pada Tabel 3), dan kebutuhan audio atau suara dalam Virtual Laboratory.

Tabel 1. Spesifikasi kebutuhan perangkat lunak

\begin{tabular}{|c|c|}
\hline Variabel & Keterangan \\
\hline Sistem Operasi & Windows \\
\hline Animation Developer & Adobe Flash CS6 \\
\hline Grafik Editor & Correl Draw X6, Adobe Photoshop CS6 \\
\hline Trainer kit maker & Microsoft Visio 2007 \\
\hline
\end{tabular}


Tabel 2. Spesifikasi kebutuhan perangkat keras

\begin{tabular}{|c|c|}
\hline Variabel & Keterangan \\
\hline Processor dan Memory & Pentium Core i3 dan 4 GB DDR2 \\
\hline VGA & Onboard (1 GB) \\
\hline Resolution requirement & 64 Bit \\
\hline
\end{tabular}

Tabel 3. Kebutuhan property dalam Virtual Laboratory

\begin{tabular}{|c|c|}
\hline Variabel & Keterangan \\
\hline Background & meja praktikum \\
\hline Alat ukur & frequency counter dengan mode frequency dan mode time \\
\hline Peralatan & jumper secara virtual dan power supply yang dioperasikan secara on dan off \\
praktikum & (tanpa aktivitas jumpering) \\
\hline Alat peraga & $\begin{array}{c}\text { Osilator Wien Bridge, Osilator Hartley, Osilator Colpitts, Astable Multivibrator, } \\
\text { praktikum }\end{array}$ \\
$\begin{array}{c}\text { Modul Resistor } 1 \mathrm{~K} \Omega, 10 \mathrm{~K} \Omega, 2 \mathrm{~K} \Omega, 20 \mathrm{~K} \Omega, 3 \mathrm{~K} \Omega \text { \& 30K } \Omega \text {, Modul Kapasitor 10nF, } \\
100 \mathrm{nF}, 1 \mathrm{uF}, 10 \mathrm{uF}, 100 \mathrm{uF} \& 100 \mathrm{uF}, \text { Modul Induktor 10mH \& 5mH }\end{array}$ \\
\hline
\end{tabular}

Penggunaan audio dalam Vitual Laboratory ini terdapat dalam setiap aktivitas plug and play, yakni: suara aktivitas penyambungan antar properti, suara saat menekan tombol on atau off dari power supply, suara button saat memilih praktikum osilator, suara pemindahan frequency mode ke time mode atau sebaliknya pada alat ukur frequency counter, suara saat menekan tombol close dan pemilihan button Yes atau No.

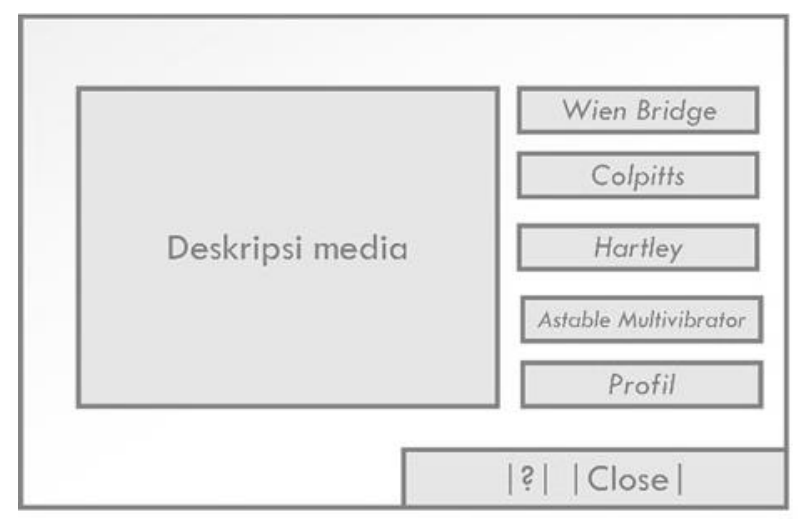

(a)

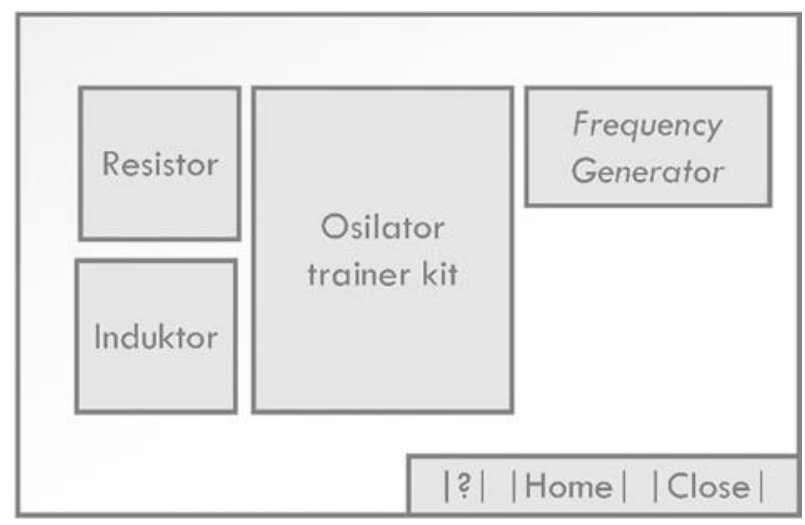

(b)

Gambar 2. Story Board dari Virtual Laboratory: (a) Tampilan halaman muka/home; (b) Tampilan halaman kerja praktikum pada masing-masing osilator 


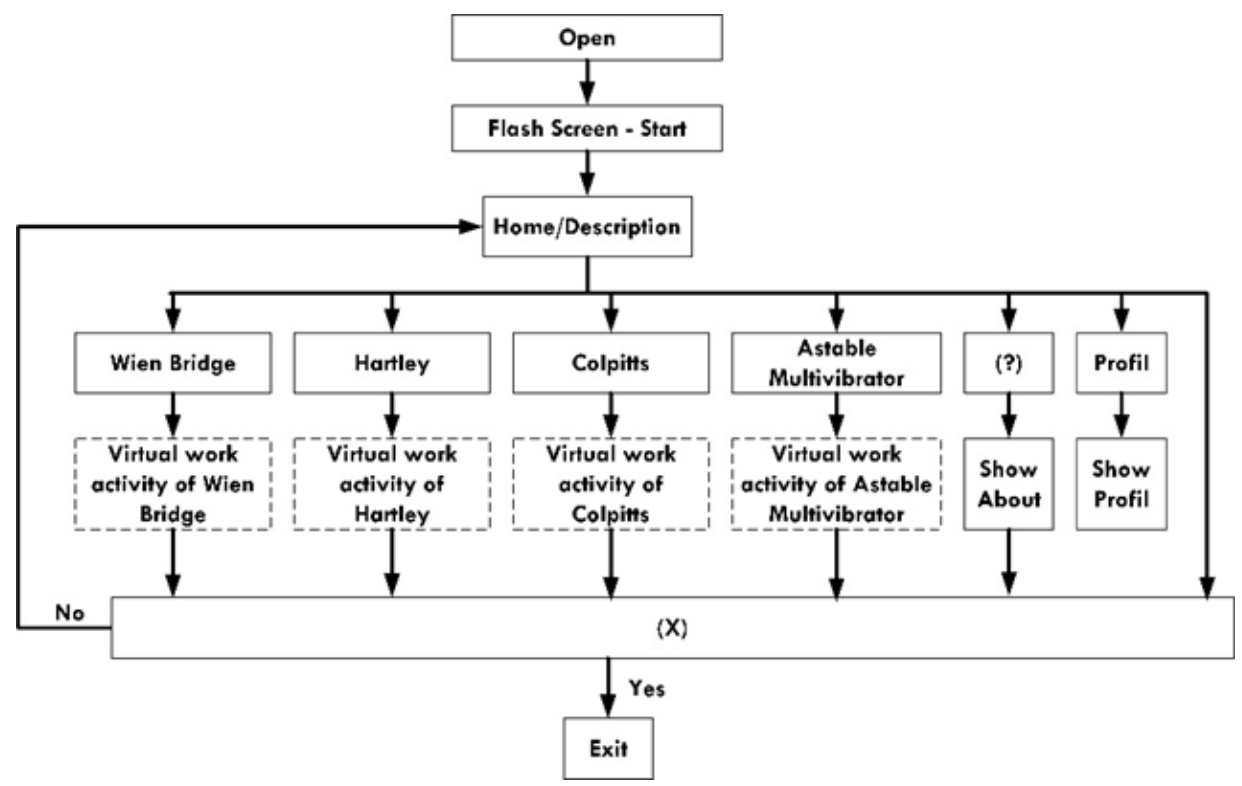

Gambar 3. Flowchart dari Virtual Laboratory

Desain tool kits osilator dan modul RLC dibuat menggunakan software microsoft visio 2007. Gambar 4 merupakan desain tool kits jenis-jenis osilator yang telah dibuat oleh peneliti.

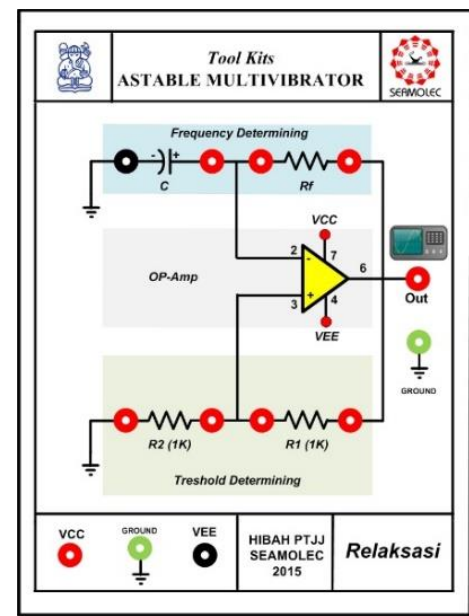

(a)

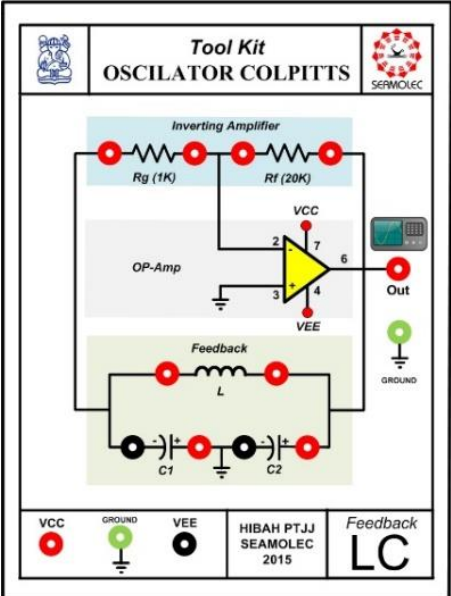

(c)

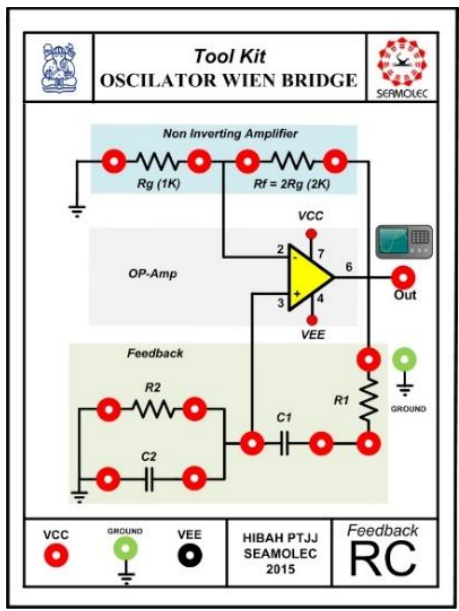

(b)

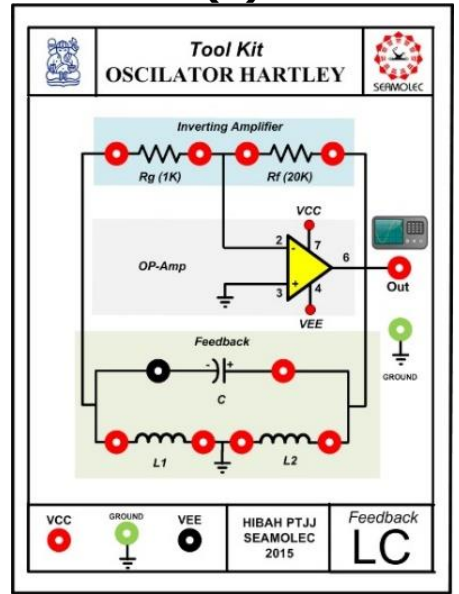

(d)

Gambar 4. Trainer kits osilator RC, LC dan Relaksasi: (a) Astable Multivibrator, (b) Wien Bridge, (c) Colpitts, dan (d) Hartley 


\section{Material Collecting}

Pada tahap ini, pengembang melakukan pembuatan bahan-bahan yang terkait dengan Virtual Laboratory ini. Pencarian logo SEAMOLEC dan logo institusi peneliti dengan bantuan search engine google, penyusunan biografi peneliti, penulisan deskrisi media dan seleksi sound. Sound tidak dibuat sendiri melainkan memakai sound yang telah tersedia di google dengan syarat tanpa watermark.

\section{Assembling}

Pada tahap ini tim membuat Virtual Laboratory dengan materi osilator analog berbasis IC OP-AMP, pembuatan tool kits masing-masing osilator beserta modul RLC menggunakan Microsoft Visio 2007, sedangkan Grafik Editor menggunakan program CorelDraw Xsuite dan Photoshop CS6. Programming dilakukan di Adobe Flash CS6. Virtual Laboratory yang dibuat ini didasarkan pada penggabungan unsur pengetahuan dengan unsur kesenangan dalam melakukan praktikum.

\section{Distribution}

Virtual Laboratory bersifat offline pada desktop, maka dari itu dalam distribusinya dapat diupload pada suatu web, sehingga peserta dapat mengunduh dan melakukan praktikum secara mandiri dimanapun berada. Pendistribusian media ini juga dapat dilakukan dengan cara sederhana yakni melalui Compact Disk atau Flash Disk.

\section{HASIL PENGEMBANGAN DAN ANALISIS}

Hasil pada penelitian ini adalah Virtual Laboratory materi osilator analog berbasis IC-OP AMP, yakni (1) Osilator Wien Bridge, (2) osilator Colpitts, (3) osilator Hartley dan (4) Astable Multivibrator. Virtual Laboratory ini terdiri dari halaman awal (flash screen), halaman utama (home), halaman praktikum dan halaman tentang pengembang. Pembuatan Virtual Laboratory ini mengacu pada story board.

Tampilan halaman flash screen (Gambar 5a) selalu muncul pada awal user membuka aplikasi. Isi dari halaman awal ini adalah copyright developer (@Syifaul Fuada, S.Pd \& Aji Widhi W, S.Kom), sponsor dan tahun pendanaannya yakni SEAMOLEC tahun 2015, serta logo afiliasi pengembang dan sponsor yakni ITB dan SEAMOLEC. Kemudian keluar tombol "masuk", praktikan harus menekan tombol "masuk" untuk menuju pilihan praktikum osilator.

Halaman utama/home (Gambar 5b) berisi pilihan praktikum yang terdiri dari (1) Osilator Wien Bridge, (2) Osilator Colpitts, (3) Osilator Hartley dan (4) Astable Multivibrator, serta profil tentang peneliti. Apabila menu ini diklik akan merujuk pada lembar kerja praktikum osilator. Misalnya seorang praktikan menekan tombol Wien bridge, maka yang muncul adalah meja kerja Wien Bridge (Gambar 5c). Modul Osilator telah disediakan langsung pada meja kerja, sehingga pengguna hanya memilih $\mathrm{R} / \mathrm{C}$ pada menu "Modul $\mathrm{R}$ " dan "Modul $\mathrm{C}$ ". Setelah dipilih $\mathrm{R} / \mathrm{C}$, praktikan melakukan aktivitas plug and play kemudian melihat hasil dari pengukuran frequency counter. Begitu halnya dengan tombol-tombol praktikum yang lainnya. Halaman profil (Gambar 5d) akan muncul apabila tombol "profil" diklik. Halaman ini menampilkan tim yang merancang produk Virtual Laboratory ini.

Help display (Gambar 5e) akan muncul apabila tombol yang bersimbol tanda tanya (?) diklik, berisi tentang petunjuk penggunaan Virtual Laboratory ini dengan benar. Apabila tombol yang bersimbol close yakni "X" (Gambar 5f) di klik, maka akan muncul sebuah pertanyaan 
dengan jawaban "ya" atau "tidak", apabila diklik tombol "ya", maka praktikan akan keluar dari Virtual Laboratory ini,

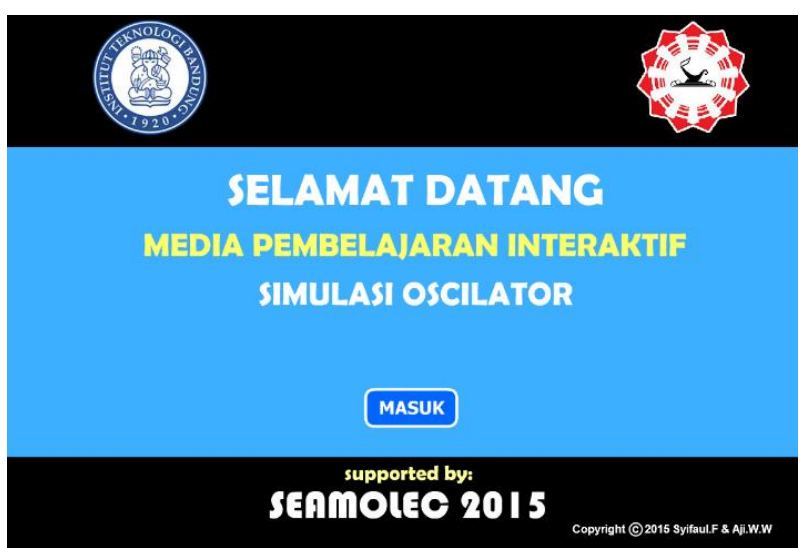

(a)

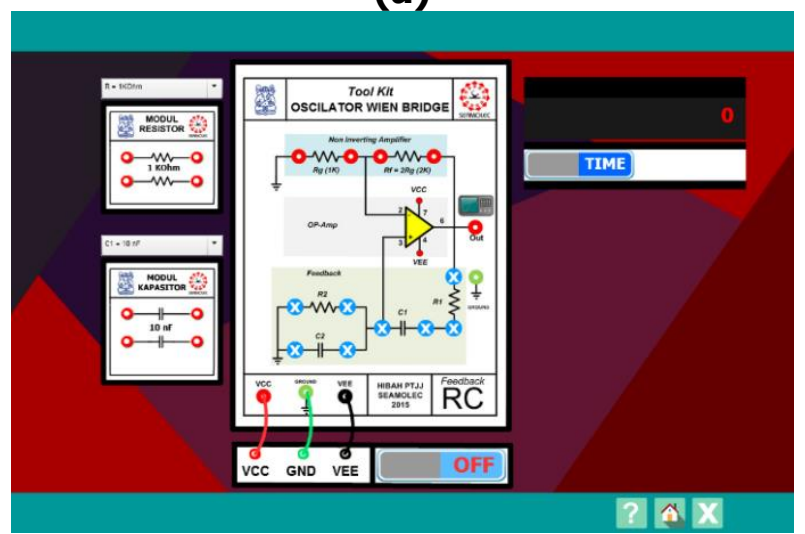

(c)

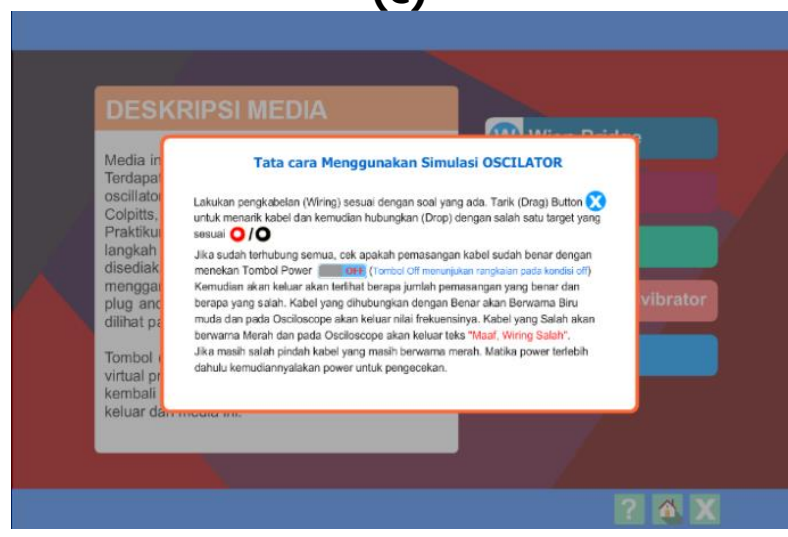

(e)

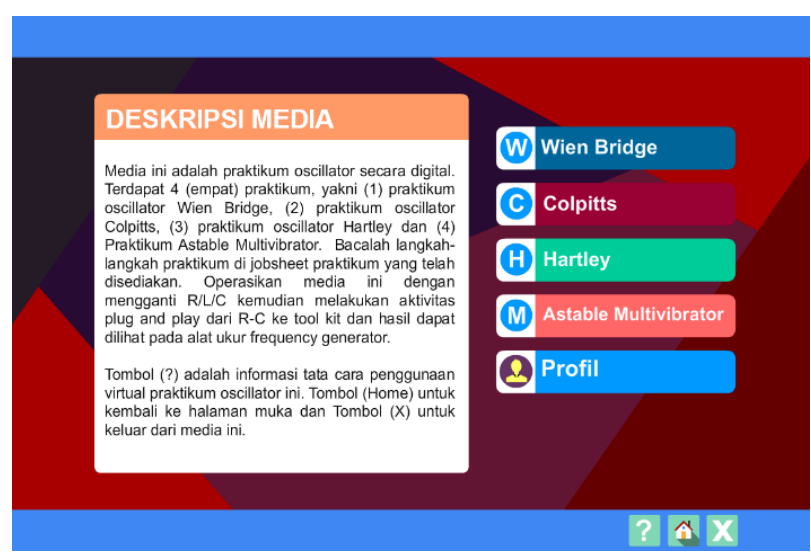

(b)

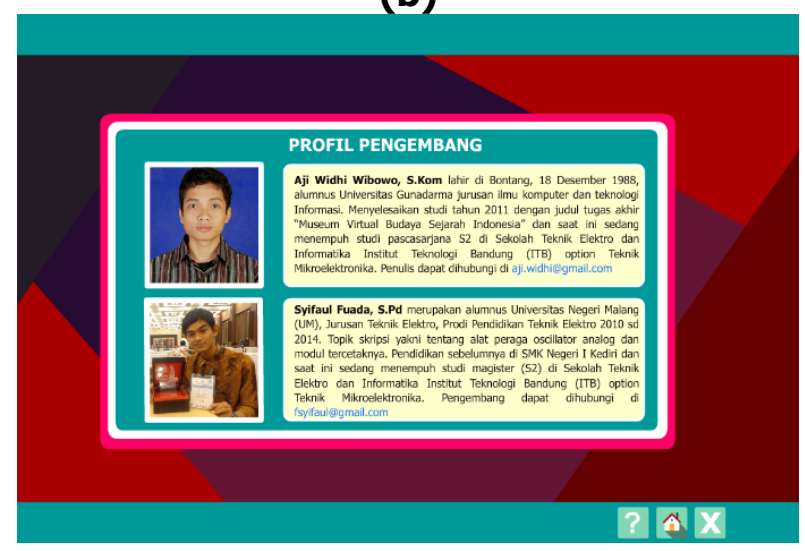

(d)

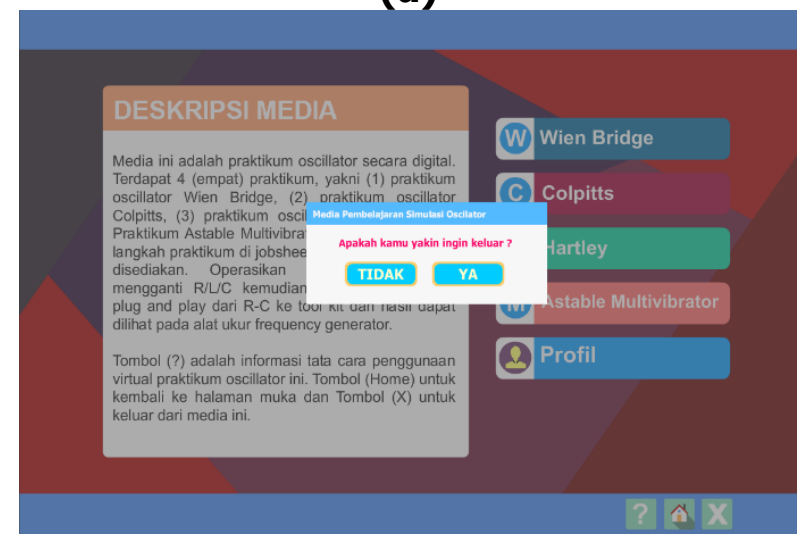

(f)

Gambar 5. Tampilan virtual laboratory: (a) flash screen; (b) Halaman muka/ home, (c) halamanlembar kerja praktikum osilator; (d) halaman tentang profil peneliti/pengembang media; (e) halaman informasi tentang tata cara penggunaan media/ help dan (f) apabila tombol close ditekan

Berdasarkan metode pengembangan, setelah selesai dalam pembuatan produk langkah selanjutnya adalah uji coba. Pengujian fungsional dari Virtual Laboratory ini dilakukan pada laptop dengan spesifikasi 64 bit dan telah terinstalasi program flash player. Pengujian ini berdasarkan decision-decision dalam teori osilator secara nyata. Pengujian pertama adalah tentang polaritas kapasitor yang memiliki kutub "+" dan "-" pada praktikum osilator Hartley 
dan Colpitts. Polaritas ini tidak boleh terbalik. Apabila terbalik maka saat power supply diubah pada posisi "on" maka frequency counter akan menampilkan teks "Maaf Rangkaian Salah" dan warna kabel menjadi warna merah. Gambar 6a merupakan uji coba kesalahan penyambungan pada praktikum osilator Hartley dan Gambar $6 \mathrm{~b}$ adalah hasil yang benar,

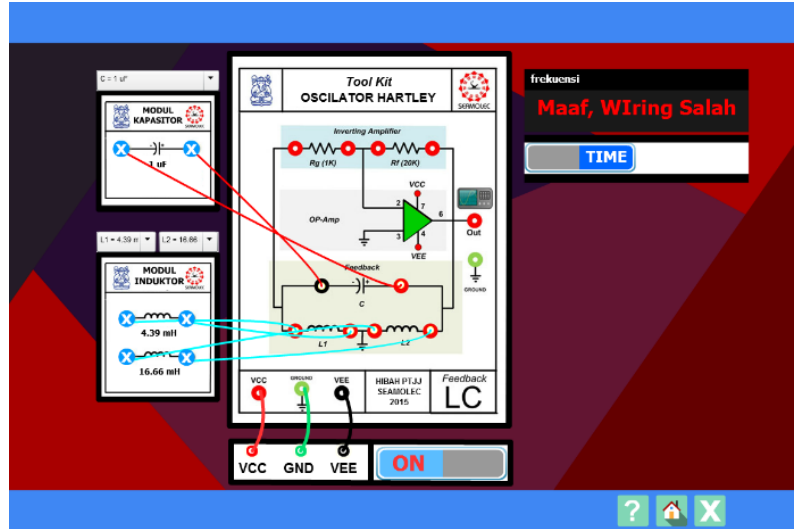

(a)

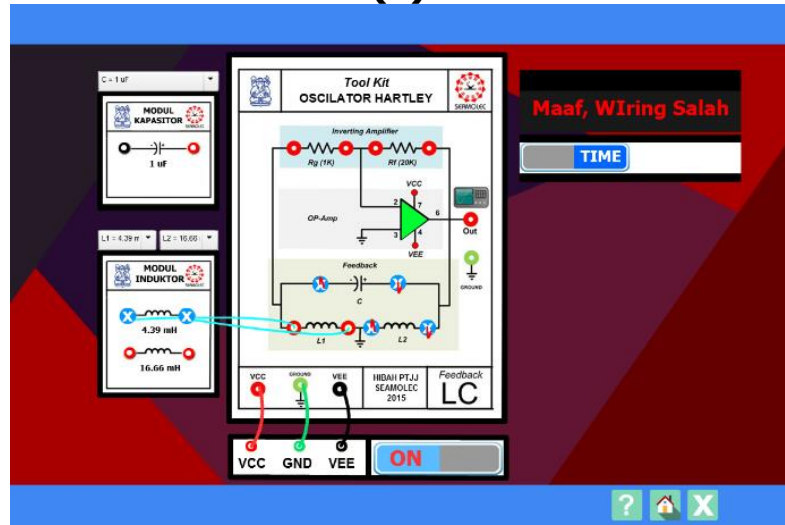

(c)

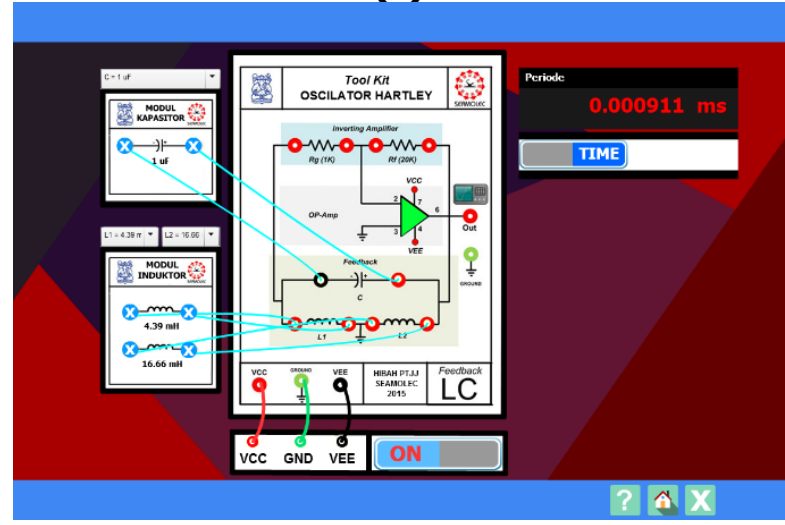

(e)

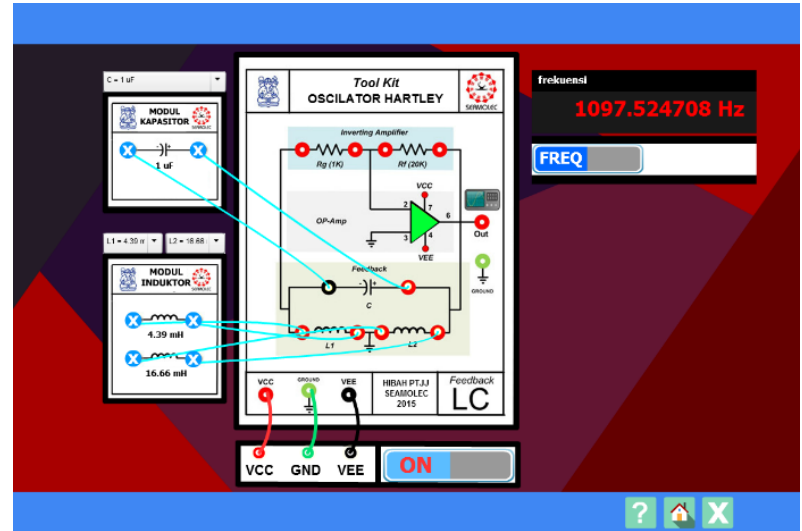

(b)

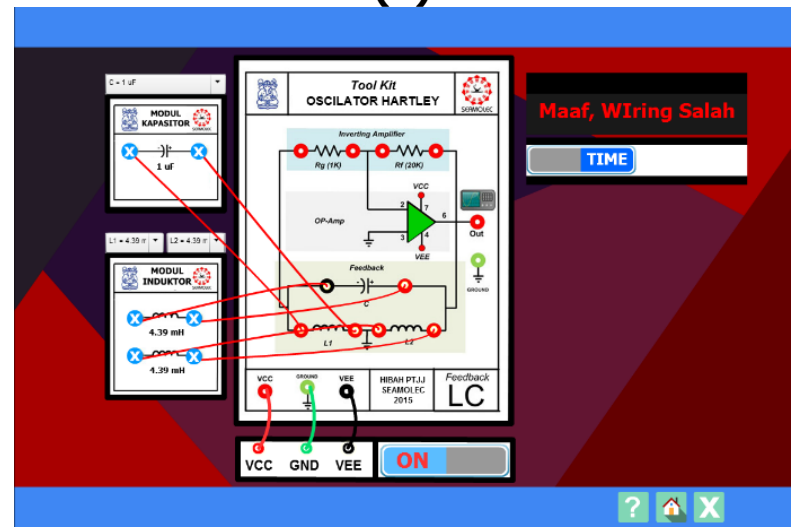

(d)

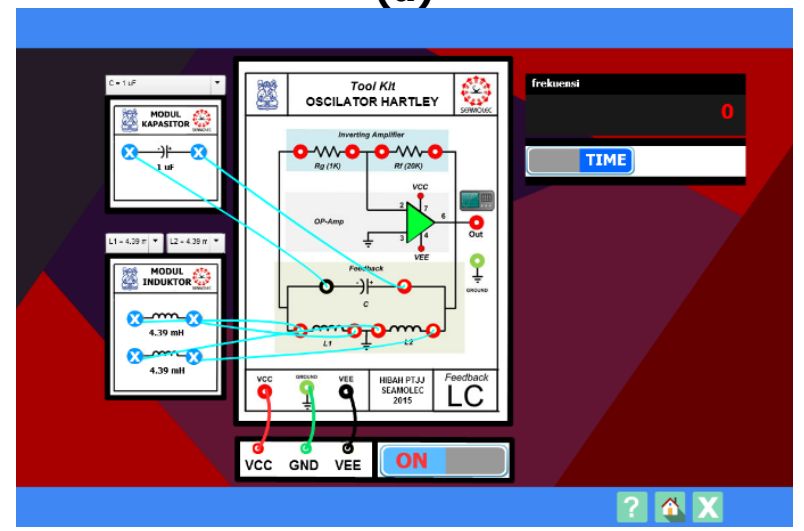

(f)

Gambar 6. Tampilan pengujian fungsional Virtual Laboratory: (a) kesalahan penyambungan polaritas kaki kapasitor elektrolit; (b) hasil praktikum yang benar pada mode frequency; (c) penyambungan kabel jumper yang tidak lengkap; (d) penyambungan kabel yang salah; (e) hasil praktikum yang benar pada mode time; penyambungan L/C yang tidak tepat pada praktikum osilator Hartley dan osilator Colpitts

Pengujian kedua adalah tentang penyambungan/wiring. Alat ukur frequency counter akan menampilkan teks "Maaf Rangkaian Salah" saat kondisi sebagai berikut: (1) penyambungan tidak sempurna (Gambar 6c), dan (2) penyambungan tidak sesuai pada target (Gambar 6d). Pengujian ketiga adalah tentang mode frequency dan time pada alat ukur frequency 
counter. Sebagai sampel uji coba, peneliti menguji virtual trainer kit osilator Hartley. Hasil mode frequency seperti ditunjukkan pada Gambar 6e, dan mode time ditunjukkan pada Gambar 6b. Pengujian keempat adalah tentang decission yang berlaku pada praktikum osilator Hartley dan osilator Colpitts. Pada osilator Hartley terdapat satu yakni syarat pemilihan L2 harus lebih besar dari L1 (baca: L2 > L1). Apabila tidak, maka saat power supply diaktifkan maka frequency counter akan menampilkan angka " $0 \mathrm{~Hz}$ " dan " $0 \mathrm{~ms}$ " dengan kata lain alat ukur tidak menunjukkan nilai frekuensi keluaran $\left(f_{0}\right)$ atau perioda $(t)$. Hal ini juga berlaku pada praktikum osilator Colpitts. Gambar $6 f$ merupakan tampilan pada praktikum osilator Hartley apabila penyambungan tidak sesuai kaidah, hasil yang benar ditunjukkan pada Gambar 6b. Pengujian kelima adalah untuk mengetahui kesesuaian antara fo hasil perhitungan teori, pengukuran menggunakan frequency counter dan hasil pengukuran pada Virtual Laboratory. Semua nilai resistor pada Virtual laboratory adalah $5 \%$ yang merupakan toleransi dari nilai sebenarnya Dan nilai semua kapasitor adalah $1 \%$ dari nilai sebenarnya. Sedangkan nilai induktor adalah nilai $100 \%$ sebenarnya. Persamaan 1 dan persamaan 2 tersebut dimasukkan ke dalam program action script pada program adobe flash.

$$
\begin{aligned}
& \text { Nilai resistor pada Vlab }=\text { Nilai resistor }-(\text { nilai resistor } \times(5 / 100)) \\
& \text { Nilai kapasitor pada Vlab }=\text { Nilai kapasitor }-(\text { nilai kapasitor } \times(1 / 100))
\end{aligned}
$$

Tabel 4 merupakan hasil komparasi dari rangkaian osilator Wien Bridge dengan parameter Rf $=2 \mathrm{~K} \Omega$ dan $\mathrm{Rg}=1 \mathrm{~K} \Omega$ (Fuada, 2014). Hasil komparasi dari rangkaian osilator Colpitts ditunjukkan pada Tabel 5 dan Tabel 6 untuk rangkaian osilator Hartley dengan parameter Rf $=20 \mathrm{~K} \Omega$ dan $\mathrm{Rg}=1 \mathrm{~K} \Omega$ (Fuada, 2016). Komparasi pengukuran Astable Multivibrator ditunjukkan pada Tabel 7 dengan parameter $\mathrm{R} 1=1 \mathrm{~K} \Omega$ dan $\mathrm{R} 2=1 \mathrm{~K} \Omega$. Berdasarkan hasil komparasi, secara keseluruhan terdapat selisih namun simpangan/error tidak terlalu jauh. Perbedaan hasil frekuensi output $\left(\mathrm{f}_{0}\right)$ ini karena pada perhitungan secara teori, toleransi dari komponen tidak diperhitungkan. Pada frequency counter dan Virtual Laboratory memperhitungkan toleransi nilai komponen (seperti pada persamaan 1 dan 2) dengan ketelitian pembacaan ukur 0,00001 atau $1 / 10^{5}$.

\begin{tabular}{|c|c|c|c|c|c|c|c|}
\hline \multirow{2}{*}{ No } & \multicolumn{2}{|c|}{$\begin{array}{l}\text { Komponen Modul } \\
\text { RC }\end{array}$} & \multirow{2}{*}{$\begin{array}{c}\text { Perhitungan } \\
\text { Teori } \\
\text { (Frequency) }\end{array}$} & \multicolumn{2}{|c|}{ Frequency counter } & \multicolumn{2}{|c|}{ Virtual Laboratory } \\
\hline & $\mathrm{R} 1, \mathrm{R} 2$ & $\mathrm{C} 1, \mathrm{C} 2$ & & Freq & Time & Freq & Time \\
\hline 1 & $1 \mathrm{~K}$ & $10 \mathrm{nF}$ & $15,92 \mathrm{KHz}$ & $13,38 \mathrm{KHz}$ & $75,24 \mu \mathrm{s}$ & $15,923 \mathrm{KHz}$ & $62,8 \mu \mathrm{s}$ \\
\hline 2 & $1 \mathrm{~K}$ & $100 \mathrm{nF}$ & $1,592 \mathrm{KHz}$ & $1,614 \mathrm{KHz}$ & $622,28 \mu \mathrm{s}$ & $1,592 \mathrm{KHz}$ & $628 \mu \mathrm{s}$ \\
\hline 3 & $10 \mathrm{~K}$ & $10 \mathrm{nF}$ & $1,592 \mathrm{KHz}$ & $1,55 \mathrm{KHz}$ & $639,5 \mu \mathrm{s}$ & $1,592 \mathrm{KHz}$ & $628 \mu \mathrm{s}$ \\
\hline 4 & $10 \mathrm{~K}$ & $100 \mathrm{nF}$ & $159,23 \mathrm{~Hz}$ & $162,78 \mathrm{~Hz}$ & $6,068 \mathrm{~ms}$ & $159,23 \mathrm{~Hz}$ & $6,28 \mathrm{~ms}$ \\
\hline 5 & $2 \mathrm{~K}$ & $10 \mathrm{nF}$ & $7,96 \mathrm{KHz}$ & $7,40 \mathrm{KHz}$ & $135,07 \mu \mathrm{s}$ & $7,961 \mathrm{KHz}$ & $125,6 \mu \mathrm{s}$ \\
\hline 6 & $2 \mathrm{~K}$ & $100 \mathrm{nF}$ & $796,1 \mathrm{~Hz}$ & $802,1 \mathrm{~Hz}$ & $1,246 \mathrm{~ms}$ & $796,1 \mathrm{~Hz}$ & $1,256 \mathrm{~ms}$ \\
\hline 7 & $20 \mathrm{~K}$ & $10 \mathrm{nF}$ & $796,1 \mathrm{~Hz}$ & $777,8 \mathrm{~Hz}$ & $1,285 \mathrm{~ms}$ & $796,2 \mathrm{~Hz}$ & $1,256 \mathrm{~ms}$ \\
\hline 8 & $20 \mathrm{~K}$ & $100 \mathrm{nF}$ & $79,61 \mathrm{~Hz}$ & $80,48 \mathrm{~Hz}$ & $12,43 \mathrm{~ms}$ & $79,62 \mathrm{~Hz}$ & $12,56 \mathrm{~ms}$ \\
\hline
\end{tabular}

Tabel 4. Hasil Percobaan Osilator Wien Bridge $\left(f=\frac{1}{2 \pi \times R C}\right)$ 
Tabel 5. Hasil Percobaan Osilator Colpitts $\left(\mathrm{f}=\frac{1}{2 \pi \times \sqrt{L C_{T}}}\right)$

\begin{tabular}{|c|c|c|c|c|c|c|c|c|}
\hline \multirow[b]{2}{*}{ No } & \multicolumn{3}{|c|}{ Komponen Modul LC } & \multirow{2}{*}{$\begin{array}{c}\text { Perhitungan } \\
\text { Teori } \\
\text { (Frequency) }\end{array}$} & \multicolumn{2}{|c|}{ Frequency counter } & \multicolumn{2}{|c|}{ Virtual Laboratory } \\
\hline & $\underset{(\mathrm{mH})}{\mathrm{L}}$ & C1 & $\mathrm{C} 2$ & & Freq & Time & Freq & Time \\
\hline 1 & 16,66 & $1 \mu \mathrm{F}$ & $1 \mu \mathrm{F}$ & $1,744 \mathrm{KHz}$ & $1,76 \mathrm{KHz}$ & $0,567 \mathrm{~ms}$ & $1,745 \mathrm{KHz}$ & $0,573 \mathrm{~ms}$ \\
\hline 2 & 16,66 & $10 \mu \mathrm{F}$ & $1 \mu \mathrm{F}$ & $1,2946 \mathrm{KHz}$ & $1,302 \mathrm{KHz}$ & $0,767 \mathrm{~ms}$ & $1,294 \mathrm{KHz}$ & $0,773 \mathrm{~ms}$ \\
\hline 3 & 16,66 & $10 \mu \mathrm{F}$ & $10 \mu \mathrm{F}$ & $550,99 \mathrm{~Hz}$ & $577,7 \mathrm{~Hz}$ & $1,73 \mathrm{~ms}$ & $551,7 \mathrm{~Hz}$ & $1,812 \mathrm{~ms}$ \\
\hline 4 & 4,39 & $1 \mu \mathrm{F}$ & $1 \mu \mathrm{F}$ & $3,4025 \mathrm{KHz}$ & $3,42 \mathrm{KHz}$ & $0,2917 \mathrm{~ms}$ & $3,399 \mathrm{KHz}$ & $0,2942 \mathrm{~ms}$ \\
\hline 5 & 4,39 & $10 \mu \mathrm{F}$ & $1 \mu \mathrm{F}$ & $2,5195 \mathrm{KHz}$ & $2,5152 \mathrm{KHz}$ & $0,3975 \mathrm{~ms}$ & $2,521 \mathrm{KHz}$ & $0,398 \mathrm{~ms}$ \\
\hline 6 & 4,39 & $10 \mu \mathrm{F}$ & $10 \mu \mathrm{F}$ & $1,0759 \mathrm{KHz}$ & $1,130 \mathrm{Khz}$ & $0,8849 \mathrm{~ms}$ & $1,075 \mathrm{KHz}$ & $0,930 \mathrm{~ms}$ \\
\hline
\end{tabular}

Tabel 6. Hasil Percobaan Osilator Hartley $\left(\mathrm{f}=\frac{1}{2 \pi \mathrm{x} \sqrt{L_{T} C}}\right)$

\begin{tabular}{|c|c|c|c|c|c|c|c|c|}
\hline \multirow[b]{2}{*}{ No } & \multicolumn{3}{|c|}{ Komponen Modul LC } & \multirow{2}{*}{$\begin{array}{c}\text { Perhitungan } \\
\text { Teori } \\
\text { (frequency) }\end{array}$} & \multicolumn{2}{|c|}{ Frequency Counter } & \multicolumn{2}{|c|}{ Virtual Laboratory } \\
\hline & $\begin{array}{c}\mathrm{L} 1 \\
(\mathrm{mH})\end{array}$ & $\begin{array}{c}\mathrm{L} 2 \\
(\mathrm{mH})\end{array}$ & C & & Freq & Time & Freq & Time \\
\hline 1 & 4,39 & 16,66 & $1 \mu \mathrm{F}$ & $1,0989 \mathrm{KHz}$ & 1,1 & 0,0 & 1,0 & 0,9 \\
\hline 2 & 4,39 & 16,66 & $10 \mu \mathrm{F}$ & $\mathrm{tz}$ & 35 & 2, & $\mathrm{tz}$ & $\mathrm{ms}$ \\
\hline 3 & 4,39 & 16,66 & $100 \mu \mathrm{F}$ & $109,89 \mathrm{~Hz}$ & $115,48 \mathrm{~Hz}$ & $8,66 \mathrm{~ms}$ & $109,75 \mathrm{~Hz}$ & $9,111 \mathrm{~ms}$ \\
\hline 4 & 4,39 & 16,66 & $1000 \mu \mathrm{F}$ & $34,69 \mathrm{~Hz}$ & $35,79 \mathrm{~Hz}$ & $27,94 \mathrm{~ms}$ & $34,706 \mathrm{~Hz}$ & $28,812 \mathrm{~ms}$ \\
\hline
\end{tabular}

Tabel 7. Hasil Percobaan Astable Multivibrator $\left(\mathrm{f}=\frac{1}{2,1976 \times \mathrm{RC}}\right)$

\begin{tabular}{|c|c|c|c|c|c|c|c|}
\hline \multirow{2}{*}{ No } & \multicolumn{2}{|c|}{$\begin{array}{c}\text { Komponen } \\
\text { Modul RC }\end{array}$} & \multirow{2}{*}{$\begin{array}{c}\text { Perhitungan Teori } \\
\text { (frequency) }\end{array}$} & \multicolumn{2}{|c|}{ Frequency Counter } & \multicolumn{2}{|c|}{ Virtual Laboratory } \\
\cline { 2 - 3 } \cline { 5 - 7 } & $\mathrm{Rf}$ & $\mathrm{C}$ & & Freq & Time & Freq & Time \\
\hline 1 & $2 \mathrm{~K}$ & $1 \mu \mathrm{F}$ & $227,52 \mathrm{~Hz}$ & $196,91 \mathrm{~Hz}$ & $5,078 \mathrm{~ms}$ & $227,520 \mathrm{~Hz}$ & $4,3952 \mathrm{~ms}$ \\
\hline 2 & $2 \mathrm{~K}$ & $10 \mu \mathrm{F}$ & $22,75 \mathrm{~Hz}$ & $21,55 \mathrm{~Hz}$ & $46,3 \mathrm{~ms}$ & $22,752 \mathrm{~Hz}$ & $43,952 \mathrm{~ms}$ \\
\hline 3 & $3 \mathrm{~K}$ & $100 \mathrm{nF}$ & $1,52 \mathrm{KHz}$ & $1,349 \mathrm{KHz}$ & $0,7408 \mathrm{~ms}$ & $1,5168 \mathrm{KHz}$ & $0,6592 \mathrm{~ms}$ \\
\hline 4 & $3 \mathrm{~K}$ & $1 \mu \mathrm{F}$ & $151,68 \mathrm{~Hz}$ & $135,1 \mathrm{~Hz}$ & $7,39 \mathrm{~ms}$ & $1,5168 \mathrm{KHz}$ & $6,5928 \mathrm{~ms}$ \\
\hline 5 & $10 \mathrm{~K}$ & $10 \mathrm{nF}$ & $4,550 \mathrm{KHz}$ & $3,74 \mathrm{KHz}$ & $0,2671 \mathrm{~ms}$ & $4,5504 \mathrm{KHz}$ & $0,2197 \mathrm{~ms}$ \\
\hline 6 & $10 \mathrm{~K}$ & $100 \mathrm{nF}$ & $455,04 \mathrm{~Hz}$ & $448 \mathrm{~Hz}$ & $2,23 \mathrm{~ms}$ & $455,041 \mathrm{~Hz}$ & $2,1976 \mathrm{~ms}$ \\
\hline 7 & $20 \mathrm{~K}$ & $10 \mathrm{nF}$ & $2,275 \mathrm{KHz}$ & $2,01 \mathrm{KHz}$ & $0,4955 \mathrm{~ms}$ & $2,7520 \mathrm{KHz}$ & $0,4395 \mathrm{~ms}$ \\
\hline 8 & $20 \mathrm{~K}$ & $100 \mathrm{nF}$ & $227,5 \mathrm{~Hz}$ & $227,5 \mathrm{~Hz}$ & $4,39 \mathrm{~ms}$ & $227,520 \mathrm{~Hz}$ & $4,3952 \mathrm{~ms}$ \\
\hline 9 & $30 \mathrm{~K}$ & $10 \mathrm{nF}$ & $1,516 \mathrm{KHz}$ & $1,38 \mathrm{KHz}$ & $0,7205 \mathrm{~ms}$ & $1,5168 \mathrm{KHz}$ & $0,6592 \mathrm{~ms}$ \\
\hline 10 & $30 \mathrm{~K}$ & $100 \mathrm{nF}$ & $151,6 \mathrm{~Hz}$ & $153,1 \mathrm{~Hz}$ & $6,52 \mathrm{~ms}$ & $151,680 \mathrm{~Hz}$ & $6,5928 \mathrm{~ms}$ \\
\hline
\end{tabular}

Pengujian keenam adalah Pengujian kualitas media yang meliputi kualitas suara, teks, warna latar belakang, kemudahan dioperasikan, tata letak dan lain sebagainya. Detail parameter ditunjukkan pada Tabel 8. Selanjutnya tabel komparasi antara praktikum secara nyata dan praktikum secara virtual ditunjukkan pada Tabel 9. Pada variabel "antarmuka" diperlihatkan bahwa laboratorium konvensional membutuhkan komponen alat dan bahan beserta alat ukur yang bila dibandingkan dengan laboratorium virtual kurang ergonomi dan efisien apabila diberlakukan di kelas besar (jumlah peserta didik $>50$ orang) dengan waktu yang terbatas. Pada variabel "wiring" diperlihatkan bahwa proses penyambungan antar komponen di Virtual Laboratory lebih ringkas dan hasil pengukuran mendekati realita. 
Desain dan Implementasi Virtual Laboratory Materi Osilator Analog berbasis IC OP-AMP

Tabel 8. Pengujian Virtual Laboratory materi osilator

\begin{tabular}{|l|c|l|}
\hline \multicolumn{1}{|c|}{ Variabel } & Cheklist & \multicolumn{1}{c|}{ Keterangan } \\
\hline Kualitas sound & Oke & $\begin{array}{l}\text { Penggunaan sound dalam vitual lab ini terdapat dalam setiap } \\
\text { aktivitas plug and play, button memilih praktikum dan tombol } \\
\text { close serta Yes/no. Semuanya berkualitas baik. }\end{array}$ \\
\hline Teks & Oke & $\begin{array}{l}\text { Teks yang terdapat pada vitual lab ini jelas terbaca, ukuran } \\
\text { dan warna teks tepat serta pemilihan font tepat. }\end{array}$ \\
\hline $\begin{array}{l}\text { Warna latar } \\
\text { belakang dari } \\
\text { Virtual Laboratory }\end{array}$ & Oke & $\begin{array}{l}\text { Warna latar belakang tepat, nyaman dipandang, tidak } \\
\text { timpang terhadap warna tool kits sehingga tidak } \\
\text { mengganggu saat pelaksanaan praktikum. }\end{array}$ \\
\hline $\begin{array}{l}\text { Kemudahan } \\
\text { intruksi }\end{array}$ & Oke & $\begin{array}{l}\text { Kalimat disusun dengan Bahasa yang sederhana tidak } \\
\text { berbelit-belit (to the point) disertai symbol-simbol terkait } \\
\text { sehingga intruksi mudah dipahami }\end{array}$ \\
\hline $\begin{array}{l}\text { Kesesuaian } \\
\text { dengan story } \\
\text { board }\end{array}$ & Oke & $\begin{array}{l}\text { Hasil Virtual Laboratory sesuai dengan perencanaan dalam } \\
\text { story board }\end{array}$ \\
\hline Kejelasan gambar & Oke & $\begin{array}{l}\text { Gambar-gambar pada Virtual Laboratory seperti tool kits, } \\
\text { modul RLC, tombol-tombol disajikan dengan high resolution. }\end{array}$ \\
\hline $\begin{array}{l}\text { Kemudahan } \\
\text { pengoperasian }\end{array}$ & Oke & $\begin{array}{l}\text { Virtual Laboratory mudah dioperasikan dan telah disediakan } \\
\text { intruksi apabila terdapat kendala dalam praktikum }\end{array}$ \\
\hline $\begin{array}{l}\text { Ketepatan tata } \\
\text { letak }\end{array}$ & Oke & $\begin{array}{l}\text { Tata letak Tool kits, modul } R L C \text {, menu-menu pada Virtual } \\
\text { Laboratory sehingga memudahkan navigasi dan tidak } \\
\text { membingungkan praktikan/pengguna. }\end{array}$ \\
\hline
\end{tabular}

Tabel 9. Komparasi antara hasil pengembangan virtual lab. dengan hand-on lab.

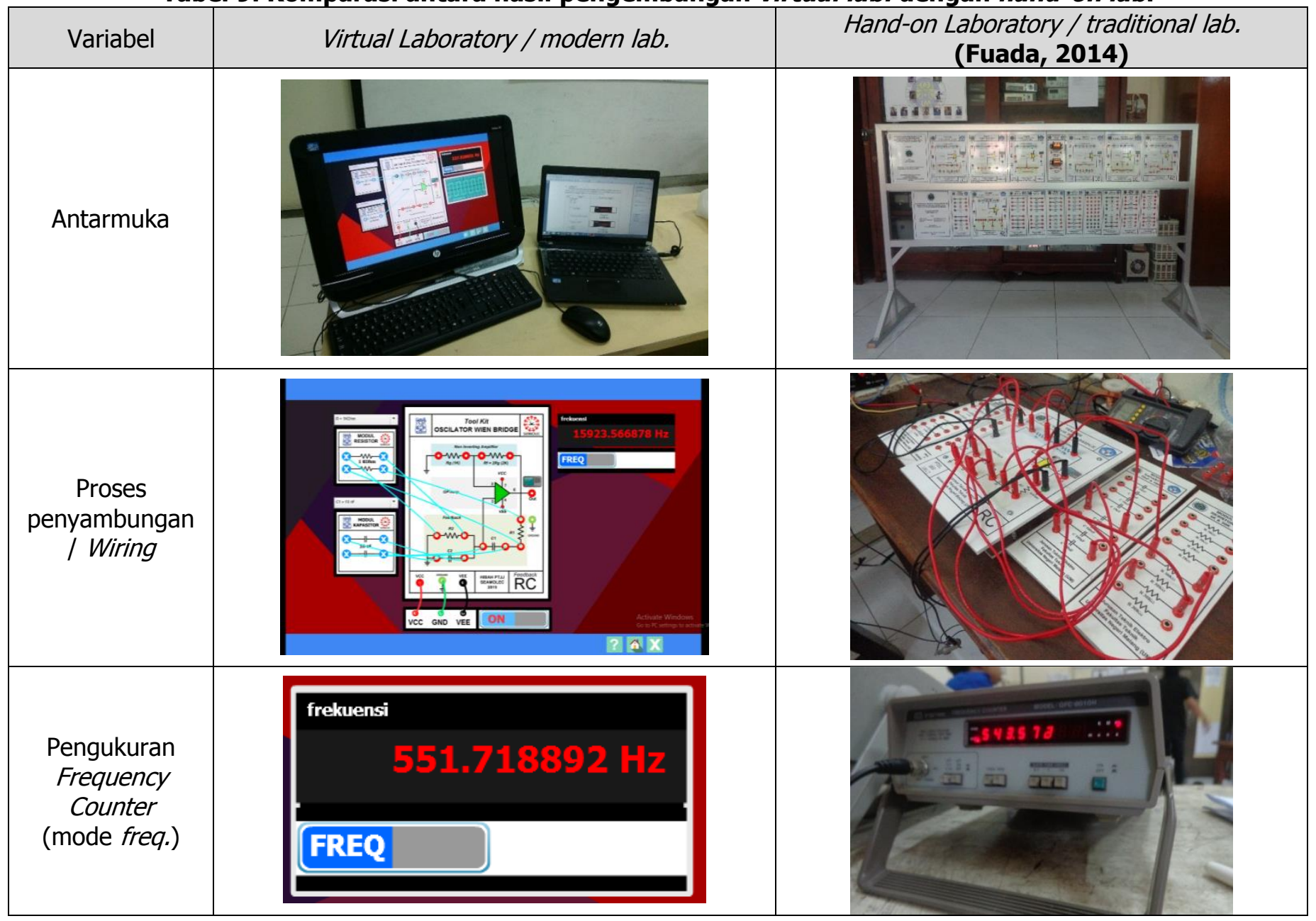




\section{PENUTUP}

\subsection{Kesimpulan}

Melalui penelitian ini telah dirancang dan dibuat sebuah media Virtual Laboratory dengan materi analog Osilator RC (osilator Wien Bridge), LC (osilator Hartley dan osilator Colpitts) dan relaksasi (Astable Multivibrator). Virtual Laboratory ini terdiri dari beberapa halaman pokok yakni: tampilan awal/pembuka (flash screen), home, halaman praktikum dan halaman tentang peneliti. Implementasi telah sesuai dengan story board. Media ini telah diuji secara fungsional agar memadai untuk dijadikan suplemen bahan ajar, yakni:

1. Pengujian kesesuaian pada variabel "polaritas kapasitor yang memiliki kutub $(+)$ dan (-)" dalam praktikum osilator Hartley dan Colpitts. Hasil uji sesuai dengan teorema.

2. Pengujian kesesuaian pada variabel "penyambungan antar komponen (wiring)". Hasil uji sesuai dengan story board.

3. Pengujian kesesuaian pada variabel "mode frequency dan time" dalam alat ukur frequency counter. Hasil uji sesuai dengan story board.

4. Pengujian kesesuaian pada variabel "Decision" yang berlaku pada praktikum osilator Hartley dan Colpitts. Hasil sesuai dengan teorema.

5. Pengujian kesesuaian pada variabel "frekuensi output $\left(f_{0}\right)$ dari masing-masing osilator dan mode time". Hasil mendekati teorema perhitungan matematis dan pengukuran secara real.

6. Pengujian pada variabel "kualitas media" yang meliputi kualitas sound, teks, warna latar belakang, kemudahan intruksi, kesesuaian dengan story board, kejelasan gambar, kemudahan pengoperasian dan tata letak. Hasil secara keseluruhan adalah baik sehingga Virtual Laboratory ini sudah dapat digunakan.

Dengan Virtual Laboratory diharapkan peserta didik dalam mendalami materi bahasan berbasis praktik tidak harus bersentuhan langsung dengan perangkat pembelajaran di laboratorium yang terbatas.

\subsection{Saran}

Agar produk yang dihasilkan dapat dimanfaatkan secara maksimal, diperlukan pengembangan lanjutan dan validasi parameter-parameternya seperti berikut:

1. Perlu ditambahkan jobsheet beserta alat evaluasi sehingga pembelajaran lebih terarah.

2. Perlu ditambahkan dengan alat ukur oscilloscope pada Virtual Laboratory sehingga peserta didik dapat melihat frekuensi yang dihasilkan oleh masing-masing osilator dalam bentuk sinyal.

3. Perlu ditambahkan pengujian variabel "Kapasitas" Virtual Laboratory untuk mengetahui bahwa aplikasi berbasis desktop ini tidak memakan memori yang besar agar ringan dijalankan sehingga RAM tidak over. Serta pengujian pada berbagai spesifikasi komputer untuk mengetahui bahwa aplikasi bersifat kompatibel.

4. Diperlukan validasi ahli, baik materi, bahasa atau media sehingga produk yang dihasilkan sesuai dengan standar\ dan juga perlu uji coba ke peserta didik sasaran/praktikan untuk mengetahui pendapat/respon akan keberadaan media tersebut.

\section{UCAPAN TERIMA KASIH}

Penelitian ini disponsori oleh Southeast Asian Ministers of Education Organzation (SEAMEO) Regional Open Learning Centre (SEAMOLEC) pada tahun 2015 melalui Hibah Penelitian Terbuka Jarak Jauh (PTJJ) berdasarkan pengumuman No. SC.8.29/10696/VI/15. 


\section{DAFTAR RUJUKAN}

Budhu, M. (2011). Virtual Laboratories for Engineering Education, International Conference of Engineering Education. pp, 1-6.

Darlis, A. R., Trisapto, P., Jambola, L. (2013). Perancangan dan Realisasi Sistem Pentransmisian Short Message dan Sinyal Digital pada Modem BPSK berbasis MATLAB. Jurnal Itenas Rekayasa. 17(1): pp, 1-12.

Fuada, S. (2013). Analisis Oscilator Astable Multivibrator IC 741UA Menggunakan Pendekatan Matlab dan Software Elektronik. Prosiding Seminar Nasional Teknologi Informasi dan Aplikasinya (SENTIA). 5: pp, A54-A60.

Fuada, S. (2014). Pengujian Trainer Oscilator Wien Bridge (Jembatan Wien) dengan Menggunakan Osciloskop dan Frekuensi Counter. Prosiding Seminar Nasional Teknologi Informasi dan Aplikasinya (SENTIA). 6: pp, A32-A36.

Fuada, S. (2014). Pengembangan Trainer Pembangkit Sinyal (Oscilator) di Jurusan Teknik Elektro Fakultas Teknik Universitas Negeri Malang (UM). Skripsi Jurusan Teknik Elektro Fakultas Teknik UM, Skripsi tidak diterbitkan.

Fuada, S., Elmunsyah, H., Suwasono. (2016), Design and Fabrication of LC Oscillator Tool Kits Based Op-Amp for Engineering Education Purpose. 17(1): pp,88-100.

Hadi, S., A. (2003). Multimedia Interaktif dan Flash. Yogyakarta: PT Graha iImu. Yogyakarta.

Jaya, H. (2012). Virtual Laboratory Development For Practicum And Facilitating Character Education In Vocational High School. Jurnal Pendidikan Vokasi. 2(1): pp, 81-91.

Kharisma, W., A., Utama, J. (2013). Portable Digital Oscilloscope Based on PIC18F4550. Telekontran, 1(2): 39-49.

Mancini, R., Palmer, R. (2001). Sine-Wave Oscillator: Introduction. Texas Instrument Application Report. SLOA060 March 2001. pp, 3.

Nurhayati. (2013). Penggunaan Media Animasi Berbasis Visual Basic (VBA) Spreadsheet Excel Untuk Meningkatkan Penguasaan Konsep Mahasiswa Pada Materi Potensial Osilator Harmonik Sederhana. Jurnal Edukasi Matematika dan Sains. 3(1): 54-61.

Potkonjak, Veljko, dkk. (2016). Virtual laboratories for education in science, technology, and engineering: A review. ELSEVIER Computers \& Education. 95: pp, 309-327.

Reimers, S., Steward, N. (2007). Adobe Flash as a Medium for Online Experimentation: a Test of Reaction Time Measurement Capabilities. Behavior Research Methods, 39(3): $\mathrm{pp}, 365-370$.

Supriandani, Y., Budiawan, I., Ekawati, E. (2015). Perancangan dan Implementasi Osiloskop Digital Berbasis Soundcard. Prosiding Seminar Nasional Instrumentasi, Kontrol dan Otomasi (SNIKO). pp, 167-173. 